\title{
Exploiting PLGA-Based Biocompatible Nanoparticles for Next-Generation Tolerogenic Vaccines against Autoimmune Disease
}

\author{
Giuseppe Cappellano ${ }^{1,2,3, *}$, Cristoforo Comi ${ }^{2,3,4} \mathbb{C}$, Annalisa Chiocchetti ${ }^{1,2,3}$ and \\ Umberto Dianzani ${ }^{1,2,3}$ \\ 1 Department of Health Sciences, Università del Piemonte Orientale, 28100 Novara, Italy; \\ annalisa.chiocchetti@med.uniupo.it (A.C.); umberto.dianzani@med.uniupo.it (U.D.) \\ 2 Interdisciplinary Research Center of Autoimmune Diseases, Università del Piemonte Orientale, \\ 28100 Novara, Italy; cristoforo.comi@med.uniupo.it \\ 3 Center for Translational Research on Autoimmune and Allergic Disease-CAAD, \\ Università del Piemonte Orientale, 28100 Novara, Italy \\ 4 Department of Translational Medicine, Università del Piemonte Orientale, 28100 Novara, Italy \\ * Correspondence: giuseppe.cappellano@med.uniupo.it; Tel.: +39-0321-660868
}

Received: 26 November 2018; Accepted: 2 January 2019; Published: 8 January 2019

\begin{abstract}
Tolerogenic vaccines are aimed at inhibiting antigen-specific immune responses. Antigen-loaded nanoparticles (NPs) have been recently emerged as ideal tools for tolerogenic vaccination because their composition, size, and capability of loading immunomodulatory molecules can be readily exploited to induce peripheral tolerance. Among polymeric NPs, poly(lactic-co-glycolic acid) (PLGA) NPs have the advantage of currently holding approval for several applications in drug delivery, diagnostics, and other clinical uses by the Food and Drug Administration (FDA). PLGA-NPs are non-toxic and display excellent biocompatibility and biodegradability properties. Moreover, surface functionalization may improve their interaction with biological materials, thereby optimizing targeting and performance. PLGA-NPs are the most extensively studied in pre-clinical model in the field of tolerogenic vaccination. Thus, this review describes their potential applications in the treatment of autoimmune diseases.
\end{abstract}

Keywords: nanoparticle; PLGA; tolerogenic vaccination; inverse adjuvant

\section{Immunogenic and Tolerogenic Vaccinations}

The immune response is normally triggered only by dangerous antigens, where the danger (i.e., pathogen) is recognized because of its ability to induce inflammation either directly or indirectly by inducing tissue necrosis. Thus, pathogens activate effector lymphocytes, which in turn support inflammation to eliminate these invaders. After this initial phase, effector lymphocytes are for the most part eliminated with the exception of an expanded set of long-lived memory lymphocytes that confers immunological memory ensuring a rapid immune response following re-exposure to the same pathogen.

T-cell activation is critical for the initiation and regulation of the immune response, it involves interaction with an antigen presenting cell (APC) and needs three signals (Figure 1). Signal 1 is delivered by the interaction of the T-cell receptor (TCR) with the antigen presented on major histocompatibility complex (MHC) molecules expressed by APC. Signal 2 is mediated by the engagement of co-stimulatory molecules such as B7.1 (CD80) and B7.2 (CD86) on APC and CD28 on the T cell. These two signals start a cross-talk between T cells and APCs which both release cytokines that collectively will define the inflammatory milieu (signal 3). According to it, $\mathrm{T}$ cells can 
differentiate into different types of cytokine-secreting cells [1,2]. The presence of interferon (IFN)- $\gamma$ drives differentiation of T helper (Th) type 1 (Th1) cells, which mainly secrete IFN- $\gamma$ and interleukin (IL)-2, and support activation of macrophages, natural killer (NK), and cytotoxic T lymphocytes [3]; IL-4 drives differentiation of Th2 cells which mainly secrete IL-4 and support B cell activation and antibody production [4]. In the absence of IFN- $\gamma$ and IL-4, transforming growth factor (TGF)- $\beta$ and IL-1 drive differentiation of Th17 cells, which mainly secrete IL-17 and support the neutrophil response [5]. When both TGF- $\beta$ and IL- 4 are present, CD4+T helper cells tend to differentiate into Th9 cells which are potent secretors of IL-9, thereby supporting the eosinophil response [6,7]. IL-6, IL-21 and IL-27 drives differentiation of $\mathrm{T}$ follicular helper (TFH) cells, which secrete IL-21, thus supporting B cell activation and germinal center formation [1]. Lastly, the presence of IL-10 drives differentiation of regulatory $\mathrm{T}$ (Treg) cells, which produce IL-10 and TGF- $\beta$, two potent inhibitors of the inflammatory and immune response [8]. Effector T cells elicit an aggressive response toward pathogens and cancer cells while Treg cells switch this response off.

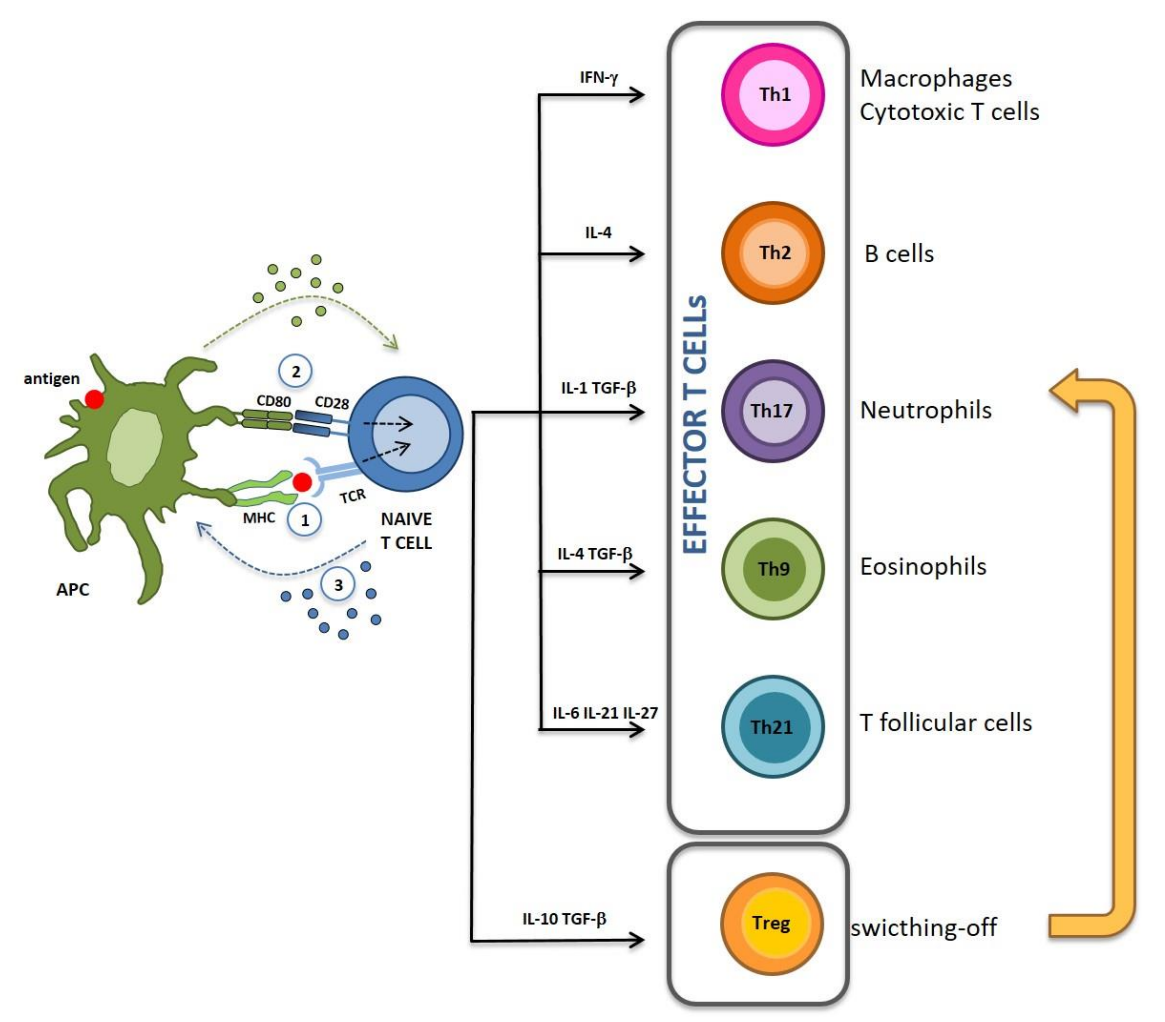

Figure 1. Activation of immune response. Upon activation by APC, naïve T cell depending on the cytokine milieu. are polarized into different T effector cell subsets (Th1, Th2, Th17, Th9, Th21) and into Treg cells, that will switch-off the antigen-specific effector response. Green and blue dotted arrows indicate signal 2 and signal 3.

Classic immunogenic vaccines induce an effector immune response and elicit immunological memory without the need for experiencing prior infection. They are composed of two components: (1) the antigen, conferring immune response specificity; and (2) the adjuvant, which has the role of keeping the vaccine into the injection site, known as the "depot effect", while triggering inflammation, necessary to promote the adaptive immune response. Specifically, adjuvants are known to activate T cells by: (1) increasing MHC-II expression thus enhancing antigen presentation APCs, which then trigger signal 1; (2) inducing APCs to express costimulatory ligands able to trigger signal 2; (3) inducing secretion of cytokines capable of directing the immune response toward appropriate effector functions (signal 3) (Figure 1). 
In contrast to immunogenic vaccines eliciting immune responses against a pathogen, tolerogenic vaccines, also known as inverse vaccines, are aimed to suppress the pathological immune response to both allergens and autoantigens. A key role in suppression of the immune response is played by Treg cells that include natural Treg (nTreg) cells, which differentiate in the thymus and mainly recognize autoantigens, and induced Treg (iTreg) cells, which differentiate in the periphery from different types of effector Th cells. Tregs exert their activity through several mechanisms, including secretion of anti-inflammatory cytokines, such as IL-10 and TGF- $\beta[9,10]$, and metabolic disruption and modulation of dendritic cell (DC) maturation and function [11]. Decreased numbers and defective function of Tregs have been detected in several inflammatory and autoimmune diseases [12]. Thus, the efficacy of several tolerogenic vaccines depends on the activation, expansion, and differentiation of antigen-specific Tregs generating a long-lasting antigen memory (dominant tolerance). Notably, Tregs can directly suppress several types of effector T cells [11] and can also inhibit APC function as attested by intravital microscopy experiments showing Tregs interaction with DC-bearing antigen prior to effector $\mathrm{T}$ cell function inhibition [13]. In addition to dominant tolerance, tolerogenic vaccines can also induce a passive or deletional tolerance leading to apoptosis or anergy of autoreactive T cells [14].

Given that high dose vaccines, intravenous and mucosal routes of administration, prolonged vaccine exposure, and the presence of IL-10 and TGF- $\beta$ are well established tolerogenic determinants, tolerogenic vaccine-induced peripheral tolerance strictly depends on antigen dose [15,16], delivery route [17], exposure time to the antigen [18] and cytokine milieu [19].

Based on this paradigm, one of the most promising approaches is represented by nanoparticles (NPs)-based vaccination. In particular, the use of NPs has greatly helped to finely tune the immunogenicity of vaccines. On the one hand, when used for immunogenic vaccination, NPs can be designed to improve antigen stability and modulate activation of innate immunity in order to elicit optimal immune responses with minimal toxicity. On the other hand, in the case of tolerogenic vaccination, NPs can be used as platforms to modulate the doses and times of delivery not only of the antigens but also of those substances needed to promote tolerance (tolerogenic adjuvants) [20] (Figure 2).

IMMUNOGENIC PLGA-NP PLATFORM
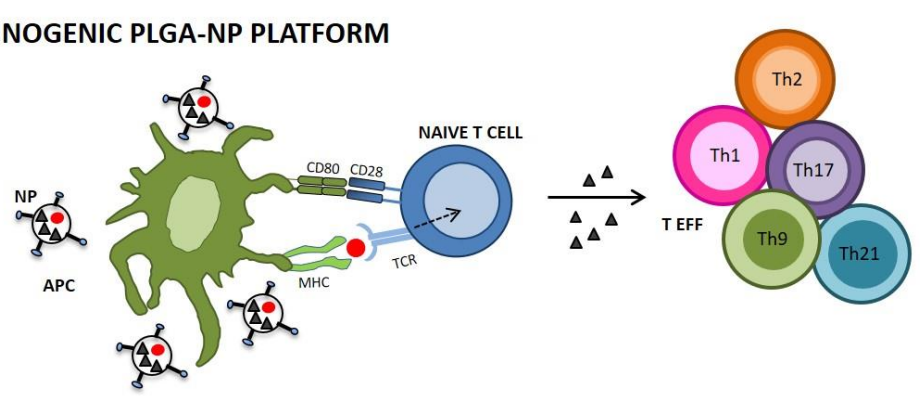

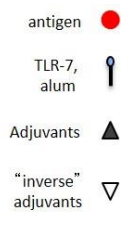

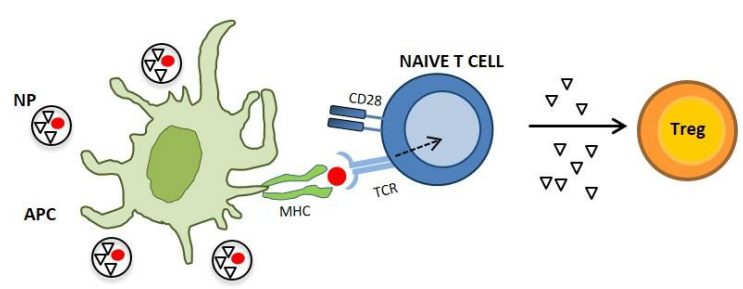

TOLEROGENIC PLGA-NP PLATFORM

Figure 2. Immunogenic and tolerogenic PLGA-NP platforms. Immunogenic PLGA-NPs may include standard adjuvants such as alum or Toll-like receptor (TLR-7) agonists, capable to activate APC and promote naïve T cell differentiation into effector cell (TEFF); on the contrary, in the absence of costimulatory signals, tolerogenic PLGA-NPs by employing "inverse adjuvants" induce tolerogenic APC that leads to the expansion of antigen-specific Treg. Dotted arrow indicates activation of naïve T cells and solid arrow indicates its differentiation into TEFF or Treg. 


\section{Nanoparticles: An Overview}

Nanomedicine holds great promise for developing new and more effective medical treatments [21,22]. In the last decade, research interest in micro/nanoparticles has rapidly increased, especially in the area of drug delivery, due to the availability of several innovative tools such as micelles, liposomes, silver and gold particles, nanocrystals, dendrimers, nanotubes, lipid NPs, and polymeric NPs, all employed as carriers for various bioactive molecules [23-28].

NPs stabilize and protect the drug from degradation and improve drug targeting to specific tissues, thereby increasing drug efficacy and reducing side effects [29]. A large number of studies have focused on anti-neoplastic drugs as many types of NPs passively increase cancer targeting due the "enhanced permeability and retention" (EPR) effect, which exploits the wide fenestrations of the angiogenic vasculature $[23,30]$. Moreover, NPs have been used to deliver DNA vectors, clinical imaging probes, and vaccine components [31-34].

Key points for their use in vaccination are their capacity to interact with several types of immune cells and encapsulate/release antigens and other immunomodulatory molecules to influence the host immune response [35]. The extent of the interaction between NPs and immune cells is determined by several intrinsic NP parameters such as size, shape, chemical composition, surface properties, charge density (i.e., zeta potential), and oxidative potential [35]. The influence of antigen-loaded NPs on the immune response can be finely modulated by changing their composition, size, and loading capacity of immunomodulatory molecules [36]. Importantly, all these features have been shown to play a role in determining either activation or shutdown of the immune response while performing immunogenic or tolerogenic vaccination, respectively.

A key characteristic of NPs that makes them particularly suited for immunogenic vaccination is the type of nanomaterial that has been used for their production. Indeed, the properties of the various nanomaterials available can significantly enhance the immune response through direct and/or indirect (i.e., cell toxicity) activation of inflammatory cells and APCs [37]. For instance, cationic (positively charged) NPs tend to induce higher inflammatory reactions than anionic (negatively charged) or neutral NPs [37-40]. Another important feature of NP-based immunogenic vaccines is represented by the size of the NP being used, which can influence biodistribution, APC uptake, and the type of Th cell responses. For example, small particles $(<50 \mathrm{~nm})$, which rapidly move to the lymph nodes and are therefore more efficiently captured by APCs, are deemed the best choice for optimal antigen presentation [41]. By contrast, large particles $(>0.5-1 \mu \mathrm{m})$, which tend to remain in the proximity of the injection site and are therefore poorly captured by APCs, are better carriers for compounds that can either support and modulate the immune response to immunogenic vaccines, as in the case of adjuvants, or trigger tolerance to tolerogenic vaccines, as in the case of inverse adjuvants $[39,42]$. Moreover, large particles tend to induce Th1, whereas small particles tend to induce Th2 responses [43].

Particular interest has been recently focused on polymeric NPs made of several biocompatible and biodegradable materials such as poly (lactic-co-glycolic acid) (PLGA)-NPs, which have been widely used to increase potency and bioavailability of several drugs and currently hold FDA approval for several therapeutic applications [44]. PLGA is a biodegradable polymer widely used in surgical sutures, bone plates, and orthopedic implants. In particular, PLGA microspheres have been used as long-acting drug delivery system since 1984. One of the key advantages of using PGLA-NPs is that they can be easily loaded with a wide variety of molecules. The degradation kinetics of NPs and the release rate of the encapsulated molecules vary depending on PGLA physicochemical properties such as lactide to glycolide ratio, molecular weight, crystal profile, storage temperature and surface coating materials [44-47]. PLGA-NPs composed of high amounts of lactic acid are soluble in dichloromethane, chloroform or acetone, while those composed of high amounts of glycolic acid are soluble in fluorinated solvents, such as hexafluoroisopropanol $[44,46]$. Low amounts of lactic acid and low molecular weight of PLGA decrease the glass transition temperature, which is usually above the physiological temperature for PLGA [48,49]. PLGA-NPs size (evaluated by dynamic laser scattering-DLS [50]) and morphology (evaluated by scanning electron microscopy-SEM, transmission 
electronic microscopy-TEM or atomic force microscopy-AFM [51]) are influenced by several synthesis parameters. For instance, the single solvent evaporation method leads to PLGA-NPs in the 1-10 $\mu \mathrm{m}$ range, whereas the double solvent method leads to PLG-NPs in nanometer scale [52]. Moreover, surface coating with poly(ethylene glycol) (PEG) makes PLGA-NPs suitable for photodynamic applications [53]. In addition, because of its excellent photostability, PLGA-NPs may be a biodegradable substitute of quantum dots in bioimaging [54]. Because of its nontoxicity and excellent biocompatibility and biodegradability, PLGA-NPs have been the most extensively studied among polymeric NPs.

This review will describe the use of PLGA-NPs for innovative generation of tolerogenic vaccines for treatment of autoimmune disease.

\section{PLGA-NPs: In Vitro and In Vivo Antigen Release}

As previously mentioned, the release of antigens from PLGA-NPs can be modulated by varying the ratio of lactide to glycolide used for the polymerization and/or the molecular weight (MW) of the polymers. For example, 85:25 PLGA copolymers (lactate:glycolate) show a slower release rate of the entrapped molecules than 50:50 PLGA copolymers [44,55,56]. PLGA-NPs are usually manufactured using a single or double solvent evaporation method, where poly/vinyl alcohol (PVA) is the commonly used surfactant $[57,58]$.

In vitro, PLGA-NPs loaded with an antigen show a bi-phasic release kinetics characterized by an initial burst release followed by a slower and more persistent release [59]. The initial burst release depends on the molecular features and concentration of the encapsulated antigen as well as on the polymer hydrophobicity [60]. It corresponds to the rapid release of the amount of antigen bound or close to the NP surface, which dissolves in the initial water entering the polymer matrix [61]. The second phase parallels a progressive slow release of soluble PLGA oligomers and monomers from the degrading polymer [62]. Antigen release slows down with the increase in NP size because of the increased diffusion lengths in larger nanoparticles [63]. Degradation of PLGA-NPs in vitro occurs through a bulk erosion mechanism [64] consisting of three phases. In the first phase, there is a decrease of molecular weight of the polymer due to the cleavage of the ester bonds, without loss of polymer mass. In the second phase, the microenvironment acidification causes polymer mass loss due to formation of oligomers. In the third phase, the oligomers are fragmented in monomers, leading to complete solubilization of the polymer [65].

Similar to the in vitro situation, PLGA-NPs are degraded in vivo through hydrolysis of the ester bonds, but this process is accelerated in this setting because tissue cells recognize the PLGA-NPs as foreign particles and react against them by releasing enzymes and free radicals promoting PLGA degradation [66]. Moreover, PLGA oligomers display increased solubility in the blood compared to the in vitro medium $[67,68]$. Lastly, cells can also directly contribute to PLGA-NP degradation by phagocytizing small PLGA-NPs and hydrolyzing them to produce lactic acid and glycolic acid, then eliminated through the Krebs cycle [69].

PLGA-NPs can be loaded with a fluorescent dye in order to monitor the release and biodistribution of the encapsulated molecules into target tissues and organs [33,70] as well as the degradation occurring in vivo. In mice, intravenous (i.v.) injection of fluorescent PLGA-NPs of two different sizes $(200 \mathrm{~nm}$ and $500 \mathrm{~nm}$ ) showed that both types of NPs display the highest deposition levels in the liver followed by the spleen and the lungs. Notably, small NPs are degraded faster than the large ones in the spleen and the liver [71,72]. A similar approach showed that small PLGA-NPs can also reach the brain [58].

\subsection{PLGA-NPs in Immunogenic Vaccination}

PLGA has an intrinsic adjuvant activity, which can increase the potency of immunogenic vaccines [73]. A pioneer study in mice showed that a single subcutaneous (s.c.) injection of ovalbumin (OVA) encapsulated into PLGA-NPs is more immunogenic than soluble OVA, as shown by the production of higher serum levels of anti-OVA immunoglobulins (IgG) [74]. This finding was confirmed by other studies where encapsulation of bovine serum albumin (BSA) into PLGA-NPs 
increased the strength of NP-mediated vaccination as judged by enhanced anti-BSA IgG levels. This vaccination was also found to be less cytotoxic than vaccination with BSA using complete Freund's adjuvant (CFA) [75-77]. Thus, it is evident that PLGA-NPs possess an intrinsic adjuvant activity due to sustained antigen release and enhanced uptake by DCs, involved in T cell activation. Moreover, PLGA-NPs are able to increase the expression of MHC class II molecules and co-stimulatory receptors (e.g., CD80 and CD86) in DCs as well as to enhance DC maturation and secretion of proinflammatory cytokines such as TNF- $\alpha$ and IL-1 $\beta$ both in vitro and in vivo [78-85], which are key factors for T cell activation. To enhance this activity, standard adjuvants, such as alum or Toll-like receptor (TLR) agonists, capable to activate DCs, have been included in the PLGA-NPs formulation [86-88].

\subsection{PLGA-NPs in Tolerogenic Vaccination}

The sustained antigen and immunomodulatory molecule release by PLGA-NPs makes these carriers a powerful tool for inverse vaccination despite their intrinsic adjuvant activity. Indeed, this intrinsic adjuvant activity can be counteracted by loading PLGA-NPs with anti-inflammatory molecules (either cytokines or drugs), which consequently act as inverse adjuvants capable of inducing tolerance. Moreover, modulating the kinetics of persistent release of the antigen makes it possible to finely tune the balance between effector and regulatory $\mathrm{T}$ cells. Indeed, transient exposure to antigens mimics microbial infections (non-self), thus inducing an effector $\mathrm{T}$ cell response, whereas persistent exposure to antigens mimics self-antigen exposure, thereby inducing a Treg-response [89].

To date, the efficacy of PLGA-NP-based tolerogenic vaccination has been demonstrated by our group [58], and others in experimental models of the following autoimmune diseases: multiple sclerosis (MS) [58,90-96], rheumatoid arthritis (RA) [97,98], and type 1 diabetes (T1D) [99-101].

\subsubsection{Experimental Autoimmune Encephalomyelitis}

MS is an autoimmune disease targeting the myelin sheaths of the central nervous system (CNS), and it is mainly ascribed to autoreactive T cells. The most common form of the disease is characterized by a relapsing/remitting (RR) course, which generally switches to a chronic progressive course several years after the onset; the minority of patients display primary chronic progressive course without the RR phase [102].

Experimental autoimmune encephalomyelitis (EAE) is a widely used animal model of MS because it shares several features with the human disease, including neurological dysfunction and perivascular inflammation in the CNS [103]. Several aspects of the role of the immune response in human MS have been ascertained thanks to the results obtained in this model. EAE can be induced in several mammalian species by immunizing animals with CNS homogenate or myelin proteins, such as myelin-oligodendrocyte glycoprotein (MOG), myelin basic protein (MBP), and proteolipid protein (PLP), or using small peptides derived from these proteins [104]. The use of different immunization protocols and genetic backgrounds allows to mimic either the RR or the progressive course.

Our group has developed PLGA-NPs loaded with either the immunodominant 35-55 epitope of MOG (MOG $35-55$ ) in C57BL/ 6 mice or IL-10, used as inverse adjuvant, for prophylactic and therapeutic treatment of a chronic progressive model of EAE [58]. We selected 65:35 PLGA-NPs because they slowly release the loaded molecule for several weeks and display minimal cell toxicity along with low intrinsic adjuvant activity. Moreover, we have shown that these PLGA-NPs loaded with IL-10 completely lose their ability to induce secretion of TNF- $\alpha$ in vitro in peripheral blood mononuclear cells. Upon s.c. injection of these PLGA-NPs loaded with either MOG $35-55$ (PLGA-MOG) or IL-10 (PLGA-IL-10), we found that simultaneous injection of both types of NPs ameliorates the course of EAE in both prophylactic and therapeutic vaccination. By contrast, immunization with only one type of these NPs (either PLGA-MOG or PLGA-IL10) did not have any effect. The positive effect on the clinical features of the disease was paralleled by decreased inflammation and T-cell infiltration in the CNS and decreased production of the proinflammatory cytokines IL-17 and IFN- $\gamma$ induced by stimulating T cells in vitro with $\mathrm{MOG}_{35-55}$ [58]. In another study, Maldonaldo and co-workers developed PLGA-NPs 
loaded with the immunodominant 139-151 epitope of PLP (PLP $139-151)$ in SJL mice together with rapamycin [90], used as inverse adjuvant, and administrated them i.v. into an RR model of EAE. Prophylactic treatment using these NPs inhibited the onset of EAE, whereas the therapeutic treatment inhibited relapse. Intriguingly, PLGA-NPs containing only $\mathrm{PLP}_{139-151}$ had a partial tolerogenic effect, which might be ascribed to the i.v. administration of this vaccine, which probably triggered higher levels of deletional tolerance than those seen after s.c. injection [90]. In support of this hypothesis, Getts et al. showed that i.v. but not s.c. injections of PLGA-NPs or polystyrene beads covalently linked to $\mathrm{MOG}_{35-55}$ on their surface display a protective effect in RR-EAE using both prophylactic and therapeutic treatments in the absence of inverse adjuvants, an effect mainly due to deletional tolerance [91].

The different requirements of tolerogenic vaccines delivered through the i.v. or s.c. routes have been nicely addressed by Casey et al [92], who studied the tolerogenic properties of PLGA-NPs loaded with PLP $139-151$ and chemically coupled to TGF- $\beta 1$ on their surface (PLGAPLP139-151-TGF- $\beta$-NPs). In preliminary experiments, these NPs were found to reduce the expression of costimulatory molecules (i.e., CD80 and CD86) in immature and mature bone marrow DCs in vitro. Working on an RR model of EAE induced with PLP ${ }_{139-151}$, these authors compared the tolerogenic activity of PLGAPLP139-151-TGF- $\beta$ NPs with that of PLGA-NPs loaded with PLP $139-151$ in the absence of TGF- $\beta$-(PLGAPLP139-151-NPs) following either i.v. or s.c. administration. Results showed that both types of NPs ameliorated EAE symptoms when administrated by i.v. injections, whereas only

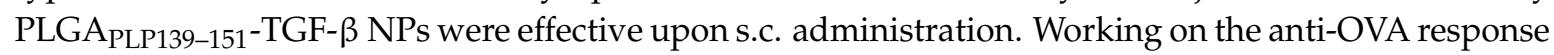
in OT-II TCR transgenic mice (which are transgenic for an anti-OVA TCR), the same lab also showed that surface binding of TGF- $\beta$ to PLGA-NPs loaded with OVA is required to efficiently induce tolerance to OVA in an antigen-specific manner [92]. These findings indicate that s.c. inverse vaccination needs inverse adjuvants in order to be effective.

The amount of antigen conjugated to NPs and the NP dose are additional key features for induction of immune tolerance, as shown by Kuo et al [93]. In this study, a single i.v. injection of high-dose PLGA-NPs carrying high amounts of PLP P $_{139-151}$ significantly decreased the severity of RR-EAE, and no relapses were observed. By contrast, i.v. injection of either low-dose PLGA-NPs carrying high amounts of PLP ${ }_{139-151}$ or high-dose PLGA-NPs carrying low amounts of PLP $139-151$ did not lead to durable tolerance, and the treated mice experienced relapses. Interestingly, high-dose PLGA-NPs loaded with high amounts of PLP ${ }_{139-151}$ substantially decreased DC expression of co-stimulatory molecules involved in activating effector $\mathrm{T}$ cell function [93].

PLGA-NPs can also be loaded with metabolic modulators that alter DC functions and promote shifting of $\mathrm{T}$ cells from the Th17 to the Treg phenotype [94]. Another approach is represented by the development of dual-sized NP/MPs platform comprising small phagocytosable particles delivering the antigen and other intracellularly active agents and large unphagocytosable particles releasing factors capable of modulating DC functions. A dual-sized PLGA platform encapsulating MOG $_{35-55}$ and vitamin D in the phagocytosable small particles, and TGF- $\beta$ and GM-CSF in the large non-phagocytosable particles was effective in treating EAE using a semi-therapeutic regimen, with an antigen-specific effect [95].

Tolerogenic PLGA-NPs can also function as direct modulators of autoreactive T cells without eliciting the intervention of tolerogenic DCs. A recent study described PLGA-NPs encapsulating TGF- $\beta$ and covered on the surface with three following types of molecules: (i) multimers of MHC class I and II molecules loaded with myelin peptides to target autoreactive T cells, (ii) anti-Fas mAb alongside a recombinant PD-L1-Fc construct, capable of inducing apoptosis or dysfunction of the autoreactive $\mathrm{T}$ cells bound to the MHC multimers, and (iii) CD47-Fc able to inhibit NP phagocytosis, thereby prolonging their activity. These NPs directly inhibited the myelin-autoreactive T cells without requiring uptake, processing, and presentation by APCs. Intravenous infusion of these multivalent NPs durably ameliorated EAE with a marked reduction in clinical, neuroinflammation, and demyelination scores [96]. 
Finally, a novel optical imaging technique was used to quantify the brain and spinal cord alterations in mice treated intravenously with PLP $\mathrm{P}_{139-151}$ chemically coupled to PLGA-NPs in a RR-EAE model. This study used imaging agents able to cross the blood brain barrier and showed that PLGA-NPs effectively inhibited both the onset of the disease and the accumulation of imaging agents into the brain and spinal cord [105].

\subsubsection{Rheumatoid Arthritis}

Rheumatoid arthritis (RA) is an autoimmune disease characterized by progressive destruction of the articular cartilage [106]. Although the etiology of RA remains unclear, type II collagen (CII) is generally considered a potential RA-associated autoantigen due to its relative abundance in the cartilage, which is an immune privileged tissue [107]. In support of this hypothesis, immunization with CII has been shown to induce an RA-like disease, named collagen-induced-arthritis (CIA), in susceptible strains of mice and rats [108]. Furthermore, Kim et al. showed that a single oral feeding with PLGA-NPs encapsulating CII in DBA/1 mice protects these mice from CIA [97]. Indeed, CII was retained up to 14 days in the dome area of Peyer's patches, where oral tolerance usually takes place. Similarly, nasal delivery of the antigen could induce antigen-specific tolerance not only locally but also in distant peripheral mucosal tissues [109]. Furthermore, Keijzer et al. showed that nasal vaccination with PLGA-NPs encapsulating the protein HSP70, which has suppressive properties, is able to reduce arthritis severity in the proteoglycan-induced arthritis (PGIA) mouse model. Finally, nasal vaccination with PLGA-NPs entrapping OVA resulted in suppression of a Th1-mediated hypersensitivity reaction against OVA in mice [98].

\subsubsection{Type 1 Diabetes}

T1D is an autoimmune disease targeting insulin-producing $\beta$ cells of the pancreatic islets and is mainly caused by autoreactive T cells recognizing several $\beta$ cell autoantigens [110].

Yoon et al., incorporated PLGA microparticles loaded with insulin in PuraMatrix ${ }^{\mathrm{TM}}$ peptide hydrogel containing GM-CSF and CpG sequences (CPG ODN1826), used to recruit and activate immune cells [99]. In this formulation, PLGA was used as a scaffold to allow infiltration of the target immune cells into the material [111]. Subcutaneous administration of this hydrogel prevented development of T1D in NOD mice, a mouse model of spontaneous T1D. Splenocytes from hydrogel-treated mice led to production of high level of IL-10 supporting tolerogenic DCs and Tregs. Moreover, multiple subcutaneous injections of this hydrogel caused formation of granulomas consisting of infiltrated immune cells, indicating the creation of a microenvironment responsible for the recruitment of immune cells and the regulation of their functions [99].

Hydrogels consist of 3-D macromolecular polymeric chains that can be easily molded in any form, shape, and size and be engineered to mimic the extracellular environment of the body's tissue. They do not dissolve and can absorb high amounts of water, which can amount to thousand folds of their own dry weight, allowing controlled release of the drugs [112]. The effectiveness of this approach was confirmed by another study using a scaffold hydrogel consisting of PLGA-NPs loaded with the BDC peptide [100]. This peptide acts as an antigen mimotope recognized by autoreactive BDC2.5 T cells in NOD mice-incorporated in alginate hydrogel loaded with GM-CSF. Upon s.c. administration to NOD mice, the majority of cells accumulating in the gel were Tregs, and these hydrogels tended to delay progression of T1D, but the effect was not significant [100].

Finally, s.c. injection of a dual-sized PLGA platform consisting of phagocytosable particles (encapsulating vitamin D3 or insulin $\mathrm{B}_{(9-23)}$ peptide) and unphagocytosable particles, encapsulating TGF- $\beta 1$ or GM-CSF, significantly protected mice from T1D development [101].

\section{Conclusions}

Current treatments for autoimmune diseases are not antigen-specific and mostly rely on the use of immunosuppressive agents, which can lead to unspecific immunosuppression and increased 
risk of infections and cancer. In contrast, tolerogenic vaccines are designed to dampen aberrant immune responses against self-antigens while preserving the immune response against foreign antigens and pathogens.

In this scenario, PLGA-NP-based tolerogenic vaccines have emerged as powerful tools to re-establish immunological tolerance, thereby preventing autoimmune disease. Given that PLGA is already approved for human use by the FDA, the possibility that the encouraging results obtained on animals using PLGA-NPs can be quickly translated to humans seems quite real. The effectiveness of PLGA-based inverse vaccination in several autoimmune disease mouse models represents a proof-of-concept that this approach is feasible, which could be extended to other experimental diseases and other NP platforms. In light of the reported literature, it is likely that the choice of different NP materials will be crucial to modulate the vaccine capacity toward different types of immunological response.

A key problem in translating reverse vaccination to humans is that in human autoimmune diseases the autoimmune response is generally heterogeneous. Furthermore, each disease can involve multiple autoantigens that can be different in different patients depending on the genetic background, age, environmental and triggering factors, and disease duration. Moreover, in chronic autoimmune disease the pattern of autoantigens recognized gradually increases during the disease course, a phenomenon known as epitope spreading. Therefore, identifying which autoantigens should be included in the tolerogenic vaccine could be quite challenging. This problem may be partly overcome by tolerance spreading, that is the gradual spread of the tolerance to the autoantigens included in the vaccine to other autoantigens involved in autoimmunity.

An alternative approach could consist in using NPs to deliver immunosuppressive substances (e.g., methotrexate and lovastatin) into the tissue targeted by the autoimmune disease, without including autoantigens in the NPs. This approach may be envisaged as a potential tolerogenic vaccination where the autoantigens are already present in the tissue, and the immunosuppressive agent functions locally as inverse adjuvant breaking the autoimmune circuits within the damaged tissues. For example, i.v. injection of multifunctional PEG-PLGA NPs (composed of lipids, folic acid and poly (cyclohexane-1,4-diylacetone dimethylene ketal)) entrapping methotrexate allowed the direct release of methotrexate into inflamed tissue and suppressed adjuvant-induced arthritis [113]. In another study, methotrexate was encapsulated in PLGA ( $\mathrm{Au}$ )/iron ( $\mathrm{Fe}) /$ gold $(\mathrm{Au})$ half shell NPs conjugated with $\alpha v \beta 3$ integrin, able to bind RGD amino acid sequences, in order to increase tissue uptake. Upon near-infrared (NIR) irradiation, the local heat generated by the NIR resonance of the $\mathrm{Au}$ half-shells leads to release of methotrexate from the PLGA-NPs into the inflamed tissue [114]. Scheinman et al. developed PLGA-NPs entrapping STAT1 siRNA and functionalized with tripeptide Arg-Gly-Asp (RGD) motifs binding to integrins. Local delivery of these NPs into the joints decreased expression of STAT1, induced regression of established arthritis in the CIA model, and increased production of IL-10 [115]. Finally, bilateral perineural administration of PLGA NPs loaded with lovastatin significantly attenuated clinical severity of experimental autoimmune neuritis (EAN), a model of Guillain-Barré syndrome and chronic inflammatory demyelinating polyradiculoneuropathy, and protected animals from peripheral nerve morphological and functional deficits [116].

In conclusion, nanotechnology is an evolving and rapidly growing technology worldwide. The relatively easy manufacturing process for PLGA-NPs and their low cost make them rather attractive for the vaccine market. Up to date, there are 15 FDA-approved PLA/PLGA-based drug products available on the US market, and they are mainly composed of anti-cancer-agents [117].

Author Contributions: All authors wrote, reviewed and edited the manuscript.

Funding: This research received no external funding.

Acknowledgments: This work was supported by Associazione Italiana Ricerca sul Cancro (IG 20714, AIRC, Milano), Fondazione Amici di Jean (Torino), and Fondazione Cariplo Ricerca biomedica sulle malattie legate all'invecchiamento (2017-0535).

Conflicts of Interest: The authors declare no conflict of interest. 


\section{Abbreviations}

$\begin{array}{ll}\text { AFM } & \text { Atomic force microscope } \\ \text { APC } & \text { Antigen-presenting cell } \\ \text { BSA } & \text { Bovine serum albumin } \\ \text { CFA } & \text { Complete Freund's adjuvant } \\ \text { CIA } & \text { Collagen-induced arthritis } \\ \text { CII } & \text { Collagen type II } \\ \text { CNS } & \text { Central nervous system } \\ \text { DC } & \text { Dendritic cells } \\ \text { EAE } & \text { Experimental autoimmune encephalomyelitis } \\ \text { EAN } & \text { Experimental autoimmune neuritis } \\ \text { EPR } & \text { Enhanced permeability and retention } \\ \text { FDA } & \text { Food and drug Administration } \\ \text { GM-CSF } & \text { Granulocyte-macrophage colony-stimulating factor } \\ \text { HSP } & \text { Heat shock protein } \\ \text { i.v. } & \text { intravenous } \\ \text { IFN } & \text { interferon } \\ \text { Ig } & \text { immunoglobulin } \\ \text { IL } & \text { interleukin } \\ \text { iTreg } & \text { Induced Treg } \\ \text { MBP } & \text { Myelin basic protein } \\ \text { MHC } & \text { Major histocompatibility complex } \\ \text { MOG } & \text { Myelin-oligodendrocyte glycoprotein } \\ \text { MS } & \text { Multiple sclerosis } \\ \text { NIR } & \text { Near-infrared } \\ \text { NK } & \text { Natural killer } \\ \text { NOD } & \text { Non Obese Diabetic } \\ \text { NPs } & \text { nanoparticles } \\ \text { nTreg } & \text { Natural Treg } \\ \text { OVA } & \text { Ovalbumin } \\ \text { PEG } & \text { Polyethylene glycol } \\ \text { PGIA } & \text { Proteoglycan-induced arthritis } \\ \text { PLGA } & \text { Poly(lactic-co-glycolic acid) } \\ \text { PLP } & \text { Proteolipid protein } \\ \text { RA } & \text { rheumatoid arthritis } \\ \text { RR } & \text { Relapse remitting } \\ \text { T.c. } & \text { subcutaneous } \\ \text { TEM } & \text { Scanning electron microscopy } \\ \text { T1D } & \text { Type 1 diabetes } \\ \text { TCR } & \text { T-cell receptor } \\ \text { Treg } & \text { Transmission electron microscope } \\ \end{array}$

\section{References}

1. Zhu, J.; Paul, W.E. Heterogeneity and plasticity of T helper cells. Cell Res. 2010, 20, 4-12. [CrossRef] [PubMed]

2. Deenick, E.K.; Ma, C.S. The regulation and role of T follicular helper cells in immunity. Immunology 2011, 134, 361-367. [CrossRef] [PubMed]

3. Bradley, L.M.; Dalton, D.K.; Croft, M. A direct role for IFN- $\gamma$ in regulation of Th1 cell development. J. Immunol. 1996, 157, 1350. [PubMed] 
4. Swain, S.L.; Weinberg, A.D.; English, M.; Huston, G. IL-4 directs the development of Th2-like helper effectors. J. Immunol. 1990, 145, 3796. [PubMed]

5. Chung, Y.; Chang, S.H.; Martinez, G.J.; Yang, X.O.; Nurieva, R.; Kang, H.S.; Ma, L.; Watowich, S.S.; Jetten, A.M.; Tian, Q.; et al. Critical regulation of early Th17 cell differentiation by interleukin-1 signaling. Immunity 2009, 30, 576-587. [CrossRef]

6. Mesturini, R.; Gigliotti, C.L.; Orilieri, E.; Cappellano, G.; Soluri, M.F.; Boggio, E.; Woldetsadik, A.; Dianzani, C.; Sblattero, D.; Chiocchetti, A.; et al. Differential induction of IL-17, IL-10, and IL-9 in human T helper cells by B7h and B7.1. Cytokine 2013, 64, 322-330. [CrossRef] [PubMed]

7. Kaplan, M.H. Th9 cells: Differentiation and disease. Immunol Rev. 2013, 252, 104-115. [CrossRef]

8. Jutel, M.; Akdis, M.; Budak, F.; Aebischer-Casaulta, C.; Wrzyszcz, M.; Blaser, K.; Akdis, C.A. IL-10 and TGF-beta cooperate in the regulatory $\mathrm{T}$ cell response to mucosal allergens in normal immunity and specific immunotherapy. Eur. J. Immunol. 2003, 33, 1205-1214. [CrossRef]

9. Asseman, C.; Mauze, S.; Leach, M.W.; Coffman, R.L.; Powrie, F. An essential role for interleukin 10 in the function of regulatory T cells that inhibit intestinal inflammation. J. Exp. Med. 1999, 190, 995-1004. [CrossRef]

10. Nakamura, K.; Kitani, A.; Fuss, I.; Pedersen, A.; Harada, N.; Nawata, H.; Strober, W. TGF-beta 1 plays an important role in the mechanism of $\mathrm{CD} 4+\mathrm{CD} 25+$ regulatory $\mathrm{T}$ cell activity in both humans and mice. J. Immunol. 2004, 172, 834-842. [CrossRef]

11. Vignali, D.A.A.; Collison, L.W.; Workman, C.J. How regulatory T cells work. Nature Rev. Immunol. 2008, 8, 523-532. [CrossRef] [PubMed]

12. Dejaco, C.; Duftner, C.; Grubeck-Loebenstein, B.; Schirmer, M. Imbalance of regulatory T cells in human autoimmune diseases. Immunology 2006, 117, 289-300. [CrossRef] [PubMed]

13. Tang, Q.; Adams, J.Y.; Tooley, A.J.; Bi, M.; Fife, B.T.; Serra, P.; Santamaria, P.; Locksley, R.M.; Krummel, M.F.; Bluestone, J.A. Visualizing regulatory $\mathrm{T}$ cell control of autoimmune responses in nonobese diabetic mice. Nat. Immunol. 2006, 7, 83-92. [CrossRef] [PubMed]

14. Lechler, R.; Chai, J.G.; Marelli-Berg, F.; Lombardi, G. The contributions of T-cell anergy to peripheral T-cell tolerance. Immunology 2001, 103, 262-269. [CrossRef] [PubMed]

15. Weiner, H.L. Induction and mechanism of action of transforming growth factor-beta-secreting Th3 regulatory cells. Immunol. Rev. 2001, 182, 207-214. [CrossRef] [PubMed]

16. Weiner, H.L. Oral tolerance: Immune mechanisms and the generation of Th3-type TGF-beta-secreting regulatory cells. Microbes Infect. 2001, 3, 947-954. [CrossRef]

17. Marelli-Berg, F.M.; Lechler, R.I. Antigen presentation by parenchymal cells: A route to peripheral tolerance? Immunol. Rev. 1999, 172, 297-314. [CrossRef]

18. Garza, K.M.; Agersborg, S.S.; Baker, E.; Tung, K.S. Persistence of physiological self antigen is required for the regulation of self tolerance. J. Immunol. 2000, 164, 3982-3989. [CrossRef]

19. Wu, J.; Xie, A.; Chen, W. Cytokine regulation of immune tolerance. Burns Trauma 2014, 2, 11-17.

20. LaMothe, R.A.; Kolte, P.N.; Vo, T.; Ferrari, J.D.; Gelsinger, T.C.; Wong, J.; Chan, V.T.; Ahmed, S.; Srinivasan, A.; Deitemeyer, P.; et al. Tolerogenic Nanoparticles Induce Antigen-Specific Regulatory T Cells and Provide Therapeutic Efficacy and Transferrable Tolerance against Experimental Autoimmune Encephalomyelitis. Front. Immunol. 2018, 9, 281. [CrossRef]

21. Emerich, D.F.; Thanos, G.C. Nanotechnology and medicine. Expert Opin. Biol. Therapy 2003, 3, 655-663. [CrossRef] [PubMed]

22. Marcato, P.D.; Durán, N. New aspects of nanopharmaceutical delivery systems. J. Nanosci. Nanotechnol. 2008, 8, 2216-2229. [CrossRef] [PubMed]

23. Stella, B.; Peira, E.; Dianzani, C.; Gallarate, M.; Battaglia, L.; Gigliotti, C.L.; Boggio, E.; Dianzani, U.; Dosio, F. Development and Characterization of Solid Lipid Nanoparticles Loaded with a Highly Active Doxorubicin Derivative. Nanomaterials (Basel) 2018, 8, 110. [CrossRef] [PubMed]

24. Clemente, N.; Ferrara, B.; Gigliotti, C.L.; Boggio, E.; Capucchio, M.T.; Biasibetti, E.; Schiffer, D.; Mellai, M.; Annovazzi, L.; Cangemi, L.; et al. Solid Lipid Nanoparticles Carrying Temozolomide for Melanoma Treatment. Preliminary In Vitro and In Vivo Studies. Int J. Mol. Sci. 2018, 19, 255. [CrossRef] [PubMed]

25. Minelli, R.; Occhipinti, S.; Gigliotti, C.L.; Barrera, G.; Gasco, P.; Conti, L.; Chiocchetti, A.; Zara, G.P.; Fantozzi, R.; Giovarelli, M.; et al. Solid lipid nanoparticles of cholesteryl butyrate inhibit the proliferation of cancer cells in vitro and in vivo models. Br. J. Pharmacol. 2013, 170, 233-244. [CrossRef] [PubMed] 
26. Gigliotti, C.L.; Minelli, R.; Cavalli, R.; Occhipinti, S.; Barrera, G.; Pizzimenti, S.; Cappellano, G.; Boggio, E.; Conti, L.; Fantozzi, R.; et al. In Vitro and In Vivo Therapeutic Evaluation of Camptothecin-Encapsulated $\beta$-Cyclodextrin Nanosponges in Prostate Cancer. J. Biomed. Nanotechnol. 2016, 12, 114-127. [CrossRef]

27. Gigliotti, C.L.; Ferrara, B.; Occhipinti, S.; Boggio, E.; Barrera, G.; Pizzimenti, S.; Giovarelli, M.; Fantozzi, R.; Chiocchetti, A.; Argenziano, M.; et al. Enhanced cytotoxic effect of camptothecin nanosponges in anaplastic thyroid cancer cells in vitro and in vivo on orthotopic xenograft tumors. Drug Deliv. 2017, 24, 670-680. [CrossRef]

28. Dianzani, C.; Foglietta, F.; Ferrara, B.; Rosa, A.C.; Muntoni, E.; Gasco, P.; Della Pepa, C.; Canaparo, R.; Serpe, L. Solid lipid nanoparticles delivering anti-inflammatory drugs to treat inflammatory bowel disease: Effects in an in vivo model. World J. Gastroenterol. 2017, 23, 4200-4210. [CrossRef]

29. Kermanizadeh, A.; Powell, L.G.; Stone, V.; Møller, P. Nanodelivery systems and stabilized solid-drug nanoparticles for orally administered medicine: Current landscape. Int. J. Nanomed. 2018, 13, 7575-7605. [CrossRef]

30. Dianzani, C.; Zara, G.P.; Maina, G.; Pettazzoni, P.; Pizzimenti, S.; Rossi, F.; Gigliotti, C.L.; Ciamporcero, E.S.; Daga, M.; Barrera, G. Drug delivery nanoparticles in skin cancers. Biomed. Res. Int. 2014, 2014, 895986. [CrossRef]

31. Xiang, S.D.; Selomulya, C.; Ho, J.; Apostolopoulos, V.; Plebanski, M. Delivery of DNA vaccines: An overview on the use of biodegradable polymeric and magnetic nanoparticles. Wiley Interdiscip. Rev. Nanomed. Nanobiotechnol. 2010, 2, 205-218. [CrossRef] [PubMed]

32. Samanta, A.; Medintz, I.L. Nanoparticles and DNA-A powerful and growing functional combination in bionanotechnology. Nanoscale 2016, 8, 9037-9095. [CrossRef] [PubMed]

33. Baetke, S.C.; Lammers, T.; Kiessling, F. Applications of nanoparticles for diagnosis and therapy of cancer. Br. J. Radiol. 2015, 88, 20150207. [CrossRef] [PubMed]

34. Leleux, J.; Roy, K. Micro and nanoparticle-based delivery systems for vaccine immunotherapy: An immunological and materials perspective. Adv. Healthc. Mater. 2013, 2, 72-94. [CrossRef] [PubMed]

35. Dobrovolskaia, M.A.; McNeil, S.E. Immunological properties of engineered nanomaterials. Nat. Nanotechnol. 2007, 2, 469-478. [CrossRef] [PubMed]

36. Kishimoto, T.K.; Maldonado, R.A. Nanoparticles for the Induction of Antigen-Specific Immunological Tolerance. Front. Immunol. 2018, 9, 230. [CrossRef]

37. Ilinskaya, A.N.; Dobrovolskaia, M.A. Immunosuppressive and anti-inflammatory properties of engineered nanomaterials. Br. J. Pharmacol. 2014, 171, 3988-4000. [CrossRef]

38. Oyewumi, M.O.; Kumar, A.; Cui, Z. Nano-microparticles as immune adjuvants: Correlating particle sizes and the resultant immune responses. Expert Rev. Vaccines 2010, 9, 1095-1107. [CrossRef]

39. Kadengodlu, P.A.; Hebishima, T.; Takeshima, S.N.; Ito, M.; Liu, M.; Abe, H.; Aida, Y.; Aigaki, T.; Ito, Y. Positively charged cholesterol-recombinant human gelatins foster the cellular uptake of proteins and murine immune reactions. Int. J. Nanomed. 2012, 7, 5437-5450.

40. Fromen, C.A.; Rahhal, T.B.; Robbins, G.R.; Kai, M.P.; Shen, T.W.; Luft, J.C.; DeSimone, J.M. Nanoparticle surface charge impacts distribution, uptake and lymph node trafficking by pulmonary antigen-presenting cells. Nanomedicine 2015, 12, 677-687. [CrossRef]

41. Manolova, V.; Flace, A.; Bauer, M.; Schwarz, K.; Saudan, P.; Bachmann, M.F. Nanoparticles target distinct dendritic cell populations according to their size. Eur. J. Immunol. 2008, 38, 1404-1413. [CrossRef] [PubMed]

42. Blank, F.; Stumbles, P.A.; Seydoux, E.; Holt, P.G.; Fink, A.; Rothen-Rutishauser, B.; Strickland, D.H.; von Garnier, C. Size-dependent uptake of particles by pulmonary antigen-presenting cell populations and trafficking to regional lymph nodes. Am. J. Respir Cell. Mol. Biol. 2013, 49, 67-77. [CrossRef] [PubMed]

43. Xiang, S.D.; Scholzen, A.; Minigo, G.; David, C.; Apostolopoulos, V.; Mottram, P.L.; Plebanski, M. Pathogen recognition and development of particulate vaccines: Doessize matter? Methods 2006, 40, 1-9. [CrossRef] [PubMed]

44. Makadia, H.K.; Siegel, S.J. Poly Lactic-co-Glycolic Acid (PLGA) as Biodegradable Controlled DrugDelivery Carrier. Polymers (Basel) 2011, 3, 1377-1397. [CrossRef] [PubMed]

45. Gentile, P.; Chiono, V.; Carmagnola, I.; Hatton, P.V. An overview of poly(lactic-co-glycolic) acid (PLGA)-based biomaterials for bone tissue engineering. Int. J. Mol. Sci. 2014, 15, 3640-3659. [CrossRef]

46. Samavedi, S.; Poindexter, L.K.; Van Dyke, M.; Goldstein, A.S. Synthetic biomaterials for regenerative medicine applications. Regen. Med. Appl. Organ. Transpl. 2014, 81-99. [CrossRef] 
47. Houchin, M.L.; Topp, E.M. Physical properties of PLGA films during polymer degradation. J. Appl. Polym. Sci. 2009, 114, 2848-2854. [CrossRef]

48. Passerini, N.; Craig, D.Q.M. An investigation into the effects of residual water on the glass transition temperature of polylactide microspheres using modulated temperature DSC. J. Control. Release 2001, 73, 111-115. [CrossRef]

49. Park, P.I.P.; Jonnalagadda, S. Predictors of glass transition in the biodegradable polylactide and poly-lactide-co-glycolide polymers. J. Appl. Polym. Sci. 2006, 100, 1983-1987. [CrossRef]

50. Carvalho, P.M.; Felício, M.R.; Santos, N.C.; Gonçalves, S.; Domingues, M.M. Application of Light Scattering Techniques to Nanoparticle Characterization and Development. Front. Chem. 2018, 6, 237. [CrossRef]

51. Balasubramanian, S.; Girija, A.R.; Nagaoka, Y.; Iwai, S.; Suzuki, M.; Kizhikkilot, V.; Yoshida, Y.; Maekawa, T.; Nair, S.D. Curcumin and 5-fluorouracil-loaded, folate- and transferrin-decorated polymeric magnetic nanoformulation: A synergistic cancer therapeutic approach, accelerated by magnetic hyperthermia. Int. J. Nanomed. 2014, 9, 437-459.

52. Swider, E.; Koshkina, O.; Tel, J.; Cruz, L.J.; de Vries, I.J.M.; Srinivas, M. Customizing poly(lactic-co-glycolic acid) particles for biomedical applications. Acta Biomater. 2018, 73, 38-51. [CrossRef] [PubMed]

53. Boix-Garriga, E.; Acedo, P.; Casadó, A.; Villanueva, A.; Stockert, J.C.; Cañete, M.; Mora, M.; Sagristá, M.L.; Nonell, S. Poly(D,L-lactide-co-glycolide) nanoparticles as delivery agents for photodynamic therapy: Enhancing singlet oxygen release and photototoxicity by surface PEG coating. Nanotechnology 2015, 26, 365104. [CrossRef] [PubMed]

54. Trofymchuk, K.; Reisch, A.; Shulov, I.; Mély, Y.; Klymchenko, A.S. Tuning the color and photostability of perylene diimides inside polymer nanoparticles: Towards biodegradable substitutes of quantum dots. Nanoscale 2014, 6, 12934-12942. [CrossRef]

55. Hussein, A.S.; Abdullah, N.; Ahmadun, F.R. In vitro degradation of poly (D,L-lactide-co-glycolide) nanoparticles loaded with linamarin. IET Nanobiotechnol. 2013, 7, 33-41. [CrossRef] [PubMed]

56. Capan, Y.; Woo, B.H.; Gebrekidan, S.; Ahmed, S.; DeLuca, P.P. Influence of formulation parameters on the characteristics of poly(D,L-lactide-co-glycolide) microspheres containing poly(L-lysine) complexed plasmid DNA. J. Control. Release 1999, 60, 279-286. [CrossRef]

57. Chaisri, W.; Hennink, W.E.; Okonogi, S. Preparation and characterization of cephalexin loaded PLGA microspheres. Curr. Drug Deliv. 2009, 6, 69-75. [CrossRef] [PubMed]

58. Cappellano, G.; Woldetsadik, A.D.; Orilieri, E.; Shivakumar, Y.; Rizzi, M.; Carniato, F.; Gigliotti, C.L.; Boggio, E.; Clemente, N.; Comi, C.; et al. Subcutaneous inverse vaccination with PLGA particles loaded with a MOG peptide and IL-10 decreases the severity of experimental autoimmune encephalomyelitis. Vaccine 2014, 32, 5681-5689. [CrossRef]

59. Hines, D.J.; Kaplan, D.L. Poly(lactic-co-glycolic) acid-controlled-release systems: Experimental and modeling insights. Crit. Rev. Ther. Drug Carrier Syst. 2013, 30, 257-276. [CrossRef]

60. Wang, J.; Wang, B.M.; Schwendeman, S.P. Characterization of the initial burst release of a model peptide from poly(D,L-lactide-co-glycolide) microspheres. J. Control. Release 2002, 82, 289-307. [CrossRef]

61. Panyam, J.; Dali, M.M.; Sahoo, S.K.; Ma, W.; Chakravarthi, S.S.; Amidon, G.L.; Levy, R.J.; Labhasetwar, V. Polymer degradation and in vitro release of a model protein from poly(D,L-lactide-co-glycolide) nano- and microparticles. J. Control. Release 2003, 92, 173-187. [CrossRef]

62. Körber, M. PLGA erosion: Solubility- or diffusion-controlled? Pharm Res. 2010, 27, 2414-2420. [CrossRef] [PubMed]

63. Klose, D.; Siepmann, F.; Elkharraz, K.; Krenzlin, S.; Siepmann, J. How porosity and size affect the drug release mechanisms from PLGA-based microparticles. Int. J. Pharm. 2006, 314, 198-206. [CrossRef] [PubMed]

64. Pitt, C.G.; Gratzl, M.M.; Kimmel, G.L.; Surles, J.; Schindler, A. Aliphatic polyesters II. The degradation of poly (DL-lactide), poly (epsilon-caprolactone), and theircopolymers in vivo. Biomaterials 1981, 2, $215-220$. [CrossRef]

65. Park, T.G. Degradation of poly(lactic-co-glycolic acid) microspheres: Effect of copolymer composition. Biomaterials 1995, 16, 1123-1130. [CrossRef]

66. Williams, D.F. Biodegradation of surgical polymers. J. Mater. Sci. 1982, 17, 1233-1246. [CrossRef]

67. Vert, M. Polyglycolide and copolyesters with lactides. In Biopolymers: Biology, Chemistry, Biotechnology, Applications; Doi, Y., Steinbuchel, A., Eds.; Wiley-VCH Verlag GmbH: Weinheim, Germany, 2002; Volume 4, pp. 179-202. 
68. Guo, L.Y.; Yan, S.Z.; Li, Q.; Xu, Q.; Lin, X.; Qi, S.S.; Yu, S.Q.; Chen, S.L. Poly(lactic-co-glycolic) acid nanoparticles improve oral bioavailability of hypocrellin A in rat. RSC Adv. 2017, 7, 42073. [CrossRef]

69. Anderson, J.M.; Shive, S.M. Biodegradation and biocompatibility of PLA and PLGA microspheres. Adv. Drug. Deliv. Rev. 1997, 28, 5-24. [CrossRef]

70. Sasaki, K.; Igarashi, M.; Hinata, M.; Komori, Y.; Fukushima, K. Simulation of Drug Release from PLGA Particles In Vivo. J. Drug Deliv. 2013, 2013, 513950. [CrossRef] [PubMed]

71. Mohammad, A.K.; Reineke, J.J. Quantitative detection of PLGA nanoparticle degradation in tissues following intravenous administration. Mol. Pharm. 2013, 10, 2183-2189. [CrossRef]

72. Lu, L.; Peter, S.J.; Lyman, M.D.; Lai, H.L.; Leite, S.M.; Tamada, J.A.; Uyama, S.; Vacanti, J.P.; Langer, R.; Mikos, A.G. In vitro and in vivo degradation of porous poly(D,L-lactic-co-glycolic acid) foams. Biomaterials 2000, 21, 1837-1845. [CrossRef]

73. Diwan, M.; Elamanchili, P.; Cao, M.; Samuel, J. Dose sparing of CpG oligodeoxynucleotide vaccine adjuvants by nanoparticle delivery. Curr. Drug Deliv. 2004, 1, 405-412. [CrossRef] [PubMed]

74. O'Hagan, D.T.; Jeffery, H.; Davis, S.S. Long-term antibody responses in mice following subcutaneous immunization with ovalbumin entrapped in biodegradable microparticles. Vaccine 1993, 11, 965-969. [CrossRef]

75. Uchida, T.; Martin, S.; Foster, T.P.; Wardley, R.C.; Grimm, S. Dose and Load Studies for Subcutaneous and Oral Delivery of Poly(lactide-co-glycolide) Microspheres Containing Ovalbumin. Pharm Res. 1994, 11, 1009-1015. [CrossRef] [PubMed]

76. Igartua, M.; Hernández, R.M.; Esquisabel, A.; Gascón, A.R.; Calvo, M.B.; Pedraz, J.L. Enhanced immune response after subcutaneous and oral immunization with biodegradable PLGA microspheres. J. Control. Release 1998, 56, 63-73. [CrossRef]

77. Ilyinskii, P.O.; Roy, C.J.; O’Neil, C.P.; Browning, E.A.; Pittet, L.A.; Altreuter, D.H.; Alexis, F.; Tonti, E.; Shi, J.; Basto, P.A.; et al. Adjuvant-carrying synthetic vaccine particles augment the immune response to encapsulated antigen and exhibit strong local immune activation without inducing systemic cytokine release. Vaccine 2014, 32, 2882-2895. [CrossRef] [PubMed]

78. Park, J.; Babensee, J.E. Differential functional effects of biomaterials on dendritic cell maturation. Acta Biomater. 2012, 8, 3606-3617. [CrossRef]

79. Elamanchili, P.; Diwan, M.; Cao, M.; Samuel, J. Characterization of poly(D,L-lactic-co-glycolic acid) based nanoparticulate system for enhanced delivery of antigens to dendritic cells. Vaccine 2004, 22, 2406-2412. [CrossRef] [PubMed]

80. Elamanchili, P.; Lutsiak, C.M.; Hamdy, S.; Diwan, M.; Samuel, J. "Pathogen-mimicking" nanoparticles for vaccine delivery to dendritic cells. J. Immunother. 2007, 4, 378-395. [CrossRef] [PubMed]

81. Yoshida, M.; Babensee, J.E. Poly(lactic-co-glycolic acid) enhances maturation of human monocyte-derived dendritic cells. J. Biomed. Mater. Res. A 2004, 71, 45-54. [CrossRef] [PubMed]

82. Raghuvanshi, R.S.; Katare, Y.K.; Lalwani, K.; Ali, M.M.; Singh, O.; Panda, A.K. Improved immune response from biodegradable polymer particles entrapping tetanus toxoid by use of different immunization protocol and adjuvants. Int. J. Pharm. 2002, 245, 109-121. [CrossRef]

83. Hamdy, S.; Molavi, O.; Ma, Z.; Haddadi, A.; Alshamsan, A.; Gobti, Z.; Elhasi, S.; Samuel, J.; Lavasanifar, A. Co-delivery of cancer-associated antigen and Toll-like receptor 4 ligand in PLGA nanoparticles induces potent CD8+ T cell-mediated anti-tumor immunity. Vaccine 2008, 26, 5046-5057. [CrossRef] [PubMed]

84. Ding, T.; Sun, J.; Zhang, P. Immune evaluation of biomaterials in TNF- $\alpha$ and IL- $\beta$ at mRNA level. J. Mater. Sci. Mater. Med. 2007, 18, 2233-2236. [CrossRef] [PubMed]

85. Sharp, F.A.; Ruane, D.; Claass, B.; Creagh, E.; Harris, J.; Malyala, P.; Singh, M.; O’Hagan, D.T.; Pétrilli, V.; Tschopp, J.; et al. Uptake of particulate vaccine adjuvants by dendritic cells activates the NALP3 inflammasome. Proc. Natl. Acad. Sci. USA 2009, 106, 870-875. [CrossRef] [PubMed]

86. Raghuvanshi, R.J.; Mistra, A.; Talwar, G.P.; Levy, R.J.; Labhasetwar, V. Enhanced immune response with a combination of alum and biodegradable nanoparticles containing tetanus toxoid. J. Microencapsul. 2001, 18, 723-732. [CrossRef] [PubMed]

87. Chen, Q.; Xu, L.; Liang, C.; Wang, C.; Peng, R.; Liu, Z. Photothermal therapy with immune-adjuvant nanoparticles together with checkpoint blockade for effective cancer immunotherapy. Nat. Commun. 2016, 7, 13193. [CrossRef] [PubMed] 
88. Ebrahimian, M.; Hashemi, M.; Maleki, M.; Hashemitabar, G.; Abnous, K.; Ramezani, M.; Haghparast, A. Co-delivery of Dual Toll-Like Receptor Agonists and Antigen in Poly(Lactic-Co-Glycolic) Acid/Polyethylenimine Cationic Hybrid Nanoparticles Promote Efficient In Vivo Immune Responses. Front. Immunol. 2017, 8, 1077. [CrossRef] [PubMed]

89. Su, L.F.; Del Alcazar, D.; Stelekati, E.; Wherry, E.J.; Davis, M.M. Antigen exposure shapes the ratio between antigen-specific Tregs and conventional T cells in human peripheral blood. Proc. Natl. Acad. Sci. USA 2016, 113, e6192-e6198. [CrossRef] [PubMed]

90. Maldonado, R.A.; LaMothe, R.A.; Ferrari, J.D.; Zhang, A.H.; Rossi, R.J.; Kolte, P.N.; Griset, A.P.; O’Neil, C.; Altreuter, D.H.; Browning, E.; et al. Polymeric synthetic nanoparticles for the induction of antigen-specific immunological tolerance. Proc. Natl. Acad. Sci. USA 2015, 112, e156-e165. [CrossRef]

91. Getts, D.R.; Martin, A.J.; McCarthy, D.P.; Terry, R.L.; Hunter, Z.N.; Yap, W.T.; Getts, M.T.; Pleiss, M.; Luo, X.; King, N.J.; et al. Microparticles bearing encephalitogenic peptides induce T-cell toleranceand ameliorate experimental autoimmune encephalomyelitis. Nat. Biotechnol. 2012, 30, 1217-1224. [CrossRef]

92. Casey, L.M.; Pearson, R.M.; Hughes, K.R.; Liu, J.M.H.; Rose, J.A.; North, M.G.; Wang, L.Z.; Lei, M.; Miller, S.D.; Shea, L.D. Conjugation of Transforming Growth Factor Beta to Antigen-Loaded Poly(lactideco-glycolide) Nanoparticles Enhances Efficiency of Antigen-Specific Tolerance. Bioconjug Chem. 2018, 29, 813-823. [CrossRef] [PubMed]

93. Kuo, R.; Saito, E.; Miller, S.D.; Shea, L.D. Peptide-Conjugated Nanoparticles Reduce Positive Co-stimulatory Expression and T Cell Activity to Induce Tolerance. Mol. Ther. 2017, 25, 1676-1685. [CrossRef] [PubMed]

94. Gammon, J.M.; Tostanoski, L.H.; Adapa, A.R.; Chiu, Y.C.; Jewell, C.M. Controlled delivery of a metabolic modulator promotes regulatory $\mathrm{T}$ cells and restrains autoimmunity. J. Control. Release 2015, 210, 169-178. [CrossRef] [PubMed]

95. Cho, J.J.; Stewart, J.M.; Drashansky, T.T.; Brusko, M.A.; Zuniga, A.N.; Lorentsen, K.J.; Keselowsky, B.G.; Avram, D. An antigen-specific semi-therapeutic treatment with local delivery of tolerogenic factors through a dual-sized microparticle system blocks experimental autoimmune encephalomyelitis. Biomaterials 2017, 143, 79-92. [CrossRef] [PubMed]

96. Pei, W.; Wan, X.; Shahzad, K.A.; Zhang, L.; Song, S.; Jin, X.; Wang, L.; Zhao, C.; Shen, C. Direct modulation of myelin-autoreactive CD4(+) and CD8(+) T cells in EAE mice by a tolerogenic nanoparticle co-carrying myelin peptide-loaded major histocompatibility complexes, CD47 and multiple regulatory molecules. Int. J. Nanomedicine. 2018, 13, 3731-3750. [CrossRef]

97. Kim, W.U.; Lee, W.K.; Ryoo, J.W.; Kim, S.H.; Kim, J.; Youn, J.; Min, S.Y.; Bae, E.Y.; Hwang, S.Y.; Park, S.H.; et al. Suppression of collagen-induced arthritis by single administration of poly(lactic-co-glycolic acid) nanoparticles entrapping type II collagen: A novel treatment strategy for induction of oral tolerance. Arthritis Rheum. 2002, 46, 1109-1120. [CrossRef]

98. Keijzer, C.; Slütter, B.; van der Zee, R.; Jiskoot, W.; van Eden, W.; Broere, F. PLGA, PLGA-TMC and TMC-TPP nanoparticles differentially modulate the outcome of nasal vaccination by inducing tolerance or enhancing humoral immunity. PLoS ONE 2011, 6, e26684. [CrossRef]

99. Yoon, Y.M.; Lewis, J.S.; Carstens, M.R.; Campbell-Thompson, M.; Wasserfall, C.H.; Atkinson, M.A.; Keselowsky, B.G. A combination hydrogel microparticle-based vaccine prevents type 1 diabetes in non-obese diabetic mice. Sci. Rep. 2015, 5, 13155. [CrossRef]

100. Verbeke, C.S.; Gordo, S.; Schubert, D.A.; Lewin, S.A.; Desai, R.M.; Dobbins, J.; Wucherpfennig, K.W.; Mooney, D.J. Multicomponent Injectable Hydrogels for Antigen-Specific Tolerogenic Immune Modulation. Adv. Healthc. Mater. 2017, 6, 1600773. [CrossRef]

101. Lewis, J.S.; Dolgova, N.V.; Zhang, Y.; Xia, C.Q.; Wasserfall, C.H.; Atkinson, M.A.; Clare-Salzler, M.J.; Keselowsky, B.G. A combination dual-sized microparticle system modulates dendritic cells and prevents type 1 diabetes in prediabetic NOD mice. Clin. Immunol. 2015, 160, 90-102. [CrossRef]

102. Goverman, J. Autoimmune T cell responses in the central nervous system. Nat. Rev. Immunol. 2009, 9, 93-407. [CrossRef] [PubMed]

103. de Rosbo, N.K.; Kaye, J.F.; Eisenstein, M.; Mendel, I.; Hoeftberger, R.; Lassmann, H.; Milo, R.; Ben-Nun, A. The myelin-associated oligodendrocytic basic protein regionMOBP15-36 encompasses the immunodominant major encephalitogenic epitope(s) for SJL/J mice and predicted epitope(s) for multiple sclerosis-associated HLA-DRB1*1501. J. Immunol. 2004, 173, 1426-1435. [CrossRef] [PubMed] 
104. Laatsch, R.; Kies Mw Gordon, S.; Alvord, E., Jr. The encephalomyelitic activity of myelin isolated by ultracentrifugation. J. Exp. Med. 1962, 115, 777-788. [CrossRef] [PubMed]

105. Eaton, V.L.; Vasquez, K.O.; Goings, G.E.; Hunter, Z.N.; Peterson, J.D.; Miller, S.D. Optical tomographic imaging of near infrared imaging agents quantifies disease severity and immunomodulation of experimental autoimmune encephalomyelitis in vivo. J. Neuroinflamm. 2013, 10, 138. [CrossRef]

106. Firestein, G.S. Evolving concepts of rheumatoid arthritis. Nature 2003, 423, 356-361. [CrossRef] [PubMed]

107. Kim, W.U.; Cho, M.L.; Jung, Y.O.; Min, S.Y.; Park, S.W.; Min, D.J.; Yoon, J.H.; Kim, H.Y. Type II collagen autoimmunity in rheumatoid arthritis. Am. J. Med. Sci. 2004, 327, 202-211. [CrossRef] [PubMed]

108. Staines, N.A.; Wooley, P.H. Collagen arthritis; what can it teach us? Br. J. Rheumatol. 1994, 33, $798-807$. [CrossRef]

109. Kiyono, H.; Fukuyama, S. NALT- versus Peyer's-patch-mediated mucosal immunity. Nat. Rev. Immunol. 2004, 4, 699-710. [CrossRef]

110. Barker, J.M. Clinical review: Type 1 diabetes-associated autoimmunity: Natural history, genetic associations, and screening. J. Clin. Endocrinol. MeTable 2006, 91, 1210-1217. [CrossRef]

111. Pan, Z.; Ding, J. Poly(lactide-co-glycolide) porous scaffolds for tissue engineering and regenerative medicine. Interface Focus 2012, 2, 366-377. [CrossRef]

112. Li, J.; Mooney, D.J. Designing hydrogels for controlled drug delivery. Nat. Rev. Mater. 2016, 1, 16071. [CrossRef] [PubMed]

113. Zhao, J.; Zhao, M.; Yu, C.; Zhang, X.; Liu, J.; Cheng, X.; Lee, R.J.; Sun, F.; Teng, L.; Li, Y. Multifunctional folate receptor-targeting and $\mathrm{pH}$-responsive nanocarriers loaded with methotrexate for treatment of rheumatoid arthritis. Int. J. Nanomed. 2017, 12, 6735-6746. [CrossRef] [PubMed]

114. Kim, H.J.; Lee, S.M.; Park, K.H.; Mun, C.H.; Park, Y.B.; Yoo, K.H. Drug-loaded gold/iron/gold plasmonic nanoparticles for magnetic targeted chemo-photothermal treatment of rheumatoid arthritis. Biomaterials 2015, 61, 95-102. [CrossRef]

115. Scheinman, R.I.; Trivedi, R.; Vermillion, S.; Kompella, U.B. Functionalized STAT1 siRNA nanoparticles regress rheumatoid arthritis in a mouse model. Nanomedicine (Lond.) 2011, 6, 1669-16682. [CrossRef] [PubMed]

116. Langert, K.A.; Goshu, B.; Stubbs, E.B. Attenuation of experimental autoimmune neuritis with locally administered lovastatin-encapsulating poly(lactic-co-glycolic) acid nanoparticles. J. Neurochem. 2016, 140, 334-346. [CrossRef]

117. Wang, Y. FDA's regulatory science program for generic PLA/PLGA-based drug products. Am. Pharm. Rev. 2016, 19, 5-9.

(C) 2019 by the authors. Licensee MDPI, Basel, Switzerland. This article is an open access article distributed under the terms and conditions of the Creative Commons Attribution (CC BY) license (http://creativecommons.org/licenses/by/4.0/). 